\title{
Establishing a large prospective clinical cohort in people with head and neck cancer as a biomedical resource: head and neck 5000
}

\author{
Andrew Robert Ness ${ }^{1 *}$, Andrea Waylen ${ }^{2}$, Katrina Hurley ${ }^{3}$, Mona Jeffreys $^{4}$, Chris Penfold ${ }^{1}$, Miranda Pring ${ }^{2}$, \\ Sam Leary ${ }^{1}$, Christine Allmark ${ }^{5}$, Stu Toms ${ }^{1}$, Susan Ring ${ }^{6}$, Tim J Peters ${ }^{7}$, Will Hollingworth ${ }^{4}$, Helen Worthington ${ }^{8}$, \\ Chris Nutting ${ }^{9}$, Sheila Fisher ${ }^{10}$, Simon N Rogers ${ }^{11}$ and Steven J Thomas ${ }^{2}$ The Head and Neck 5000 Study Team
}

\begin{abstract}
Background: Head and neck cancer is an important cause of ill health. Survival appears to be improving but the reasons for this are unclear. They could include evolving aetiology, modifications in care, improvements in treatment or changes in lifestyle behaviour. Observational studies are required to explore survival trends and identify outcome predictors.

Methods: We are identifying people with a new diagnosis of head and neck cancer. We obtain consent that includes agreement to collect longitudinal data, store samples and record linkage. Prior to treatment we give participants three questionnaires on health and lifestyle, quality of life and sexual history. We collect blood and saliva samples, complete a clinical data capture form and request a formalin fixed tissue sample. At four and twelve months we complete further data capture forms and send participants further quality of life questionnaires.

Discussion: This large clinical cohort of people with head and neck cancer brings together clinical data, patient-reported outcomes and biological samples in a single co-ordinated resource for translational and prognostic research.
\end{abstract}

Keywords: Head and neck cancer, Clinical cohort, Prognosis research, Patient-reported outcomes, Sexual history, Quality of life, Biological samples

\section{Background}

Head and neck cancer, though less common in developed countries, is an important cause of mortality and morbidity worldwide [1]. Survival is poor [2] and, despite advances in treatment, has not improved until recently [3]. The reasons for these recent improvements are unclear. They could include changes in disease aetiology or the fitness of people with disease, or alternatively, an improvement in treatment or alterations in lifestyle behaviour after treatment. The number of clinical trials carried out in people with head and neck cancer has increased over recent years but there is a need

\footnotetext{
* Correspondence: Andy.Ness@bristol.ac.uk

${ }^{1}$ National Institute for Health Research (NIHR) Biomedical Research Unit in

Nutrition, Diet and Lifestyle at the University Hospitals Bristol NHS

Foundation Trust and the University of Bristol and School of Oral and Dental

Sciences, University of Bristol, Bristol, UK

Full list of author information is available at the end of the article
}

for observational studies to explore reasons for the improved survival and to identify predictors of outcome [4].

The importance of prognosis research has been highlighted recently $[5,6]$. Some questions in prognostic research can be answered using routinely collected data or existing studies designed for other purposes [6]. Clinical cohorts, though expensive and time consuming, have a number of advantages over other study designs. These include the recruitment of a potentially broad and representative sample with limited exclusion criteria; participants with a shared (rather than staggered) clinical starting point; the measurement of prognostic factors not used in clinical practice; the inclusion of outcomes not routinely collected in existing sources (such as quality of life) and the collection of biological samples that can be analysed later. Many studies of disease prognosis have been small and their protocols have not been clearly described 
or reported [5]. There is therefore a need for welldesigned, adequately-powered studies of this kind $[5,6]$.

In this paper we describe the methods for a large UKbased clinical cohort study in head and neck cancer called Head and Neck 5000. The primary justification for this study is to evaluate the impact of centralisation of care for people with head and neck cancer; a future publication will report on this evaluation. However, we also intend to develop a well-phenotyped clinical cohort that will provide a biomedical resource for translational and prognostic research in head and neck cancer.

\section{Methods}

Head and Neck 5000 is an observational study that recruited people with head and neck cancer from across the United Kingdom. We describe the: process of designing and running the study; recruitment to the study; baseline data collection; blood and saliva samples; tissue samples; study follow-up; data management and statistical power. The study protocol, questionnaires, consent form and patient information leaflet were approved by the National Research Ethics Committee (South West Frenchay Ethics Committee, reference 10/H0107/57, $5^{\text {th }}$ November 2010) and subsequently approved by the research and development departments for all participating NHS Trusts. We will make copies of the study protocol and all documents described below available on the study website when recruitment finishes (http:// www.headandneck5000.org.uk).

\section{Designing and running the study}

We wanted to ensure that we drew on existing expertise and experience and at the same time encouraged collaboration and a sense of ownership of the study among clinicians treating people with head and neck cancer in the UK. To achieve this we had a number of preliminary discussions with key individuals and groups and hosted several workshops to bring together clinicians, methodologists and patient representatives. At these workshops we discussed and agreed both the principles and details of the study. Our aim was, as far as possible, to map the research protocol onto the treatment pathway of people with head and neck cancer and so minimise impact on both participants and clinicians. We also reduced the burden on participants by limiting the size and frequency of questionnaires, so as to encourage enrolment and continued participation. Before starting recruitment we completed a national survey of oncology centres and multi-disciplinary teams treating head and neck cancer that provided a picture of care nationally [7] We formally initiated centres before they opened to data collection and carry out visits to check on data quality. We have set up a study website, send regular newsletters to centres and provide them with individual reports on their recruitment and response rates.

\section{Recruitment to the study}

All people with a new diagnosis of head and neck cancer are eligible to join the study. People with cancers in the pharynx, mouth, larynx, salivary glands and thyroid are all included. People with lymphoma, tumours of the skin or a recurrence of a previous head and neck cancer are excluded from the study. People have to be recruited before their treatment starts, unless their cancer treatment was is their diagnostic procedure. Where this is the case participants have to be recruited within a month of the diagnostic procedure. Potential participants for whom the decision is to provide palliative support are recruited as soon after diagnosis as possible. Potentially eligible people are identified by the multi-disciplinary team treating them. A a member of the clinical team in the local centre introduces the study to potential participants and either one of the clinical team or the research nurse give them a copy of the patient information leaflet. Participants are given an opportunity to consider this leaflet. They are then approached by a research nurse based in the local centre. The nurse answers any questions they have and then obtains written informed consent to participate in the study. This consent is wide-ranging and includes agreement to: collect, store and use biological samples; obtain samples of stored tissue; carry out genetic analyses and collect information from hospital notes and through record linkage. The teams keep logs of the number of eligible people not enrolled and the reason they were not recruited. The detailed process of recruitment is adapted as necessary by centres to ensure that it maps onto local practice in each centre.

\section{Baseline data collection}

Having obtained informed consent the research nurse gives the participant three questionnaires to take away, complete and subsequently hand in to the clinic or return to the study centre in a pre-paid envelope. The research nurse offers to help complete any of the questionnaires where necessary. A more detailed summary of the contents of the questionnaires used at baseline and follow up is included in Table 1. The first questionnaire is five pages long and enquires about social and economic circumstances, overall health and lifestyle behaviours such as smoking and alcohol consumption. The second questionnaire is nine pages long and enquires about physical and psychological health, well-being and quality of life. The version of this questionnaire used in the Bristol centre contains an additional nine pages of questions on physical appearance. The third questionnaire comprises just one page and enquires about past sexual behaviours. The research nurse explains that this is because of the role of 
Table 1 Contents of questionnaires and data collection forms included in the head and neck 5000 clinical cohort study

\begin{tabular}{|c|c|c|c|c|}
\hline Questionnaire & Question set & Research topic & $\begin{array}{l}\text { Number } \\
\text { of pages }\end{array}$ & Questionnaire pack \\
\hline \multirow[t]{2}{*}{ Data capture form } & Diagnosis and treatment & $\begin{array}{l}\text { Based on the UK National Head and neck } \\
\text { Cancer Audit [8] }\end{array}$ & 1 & Baseline, 4-month, 12-month \\
\hline & Co-morbidity & Adult co-morbidity assessment 27 (ACE-27) [11] & 1 & \\
\hline Health and Lifestyle & About You & $\begin{array}{l}\text { Demographic data, Education, occupation [12], } \\
\text { Income [13], EQ5D initially then EQ-5D-5 L [14], } \\
\text { Smoking }[15,16] \text {, Alcohol }[15,16]\end{array}$ & 4 & Baseline, 4-month, 12-month \\
\hline \multirow[t]{7}{*}{ Quality of life } & Your Outlook & Revised Life Orientation Test (LOT-R) [17] & 1 & Baseline, 4-month, 12-month \\
\hline & Your General Health & EORTC QLQ-C30 [18] & 2.5 & Baseline, 4-month, 12-month \\
\hline & $\begin{array}{l}\text { Specific Aspects of } \\
\text { Your Health }\end{array}$ & EORTC QLQ-H\&N35 [19] & 2 & Baseline, 4-month, 12-month \\
\hline & Your Feelings & Hospital Anxiety and Depression Scale (HADS) [20] & 2 & Baseline, 4-month, 12-month \\
\hline & Your Diet & $\begin{array}{l}\text { Three items (fruit, vegetables and deep fried food) } \\
\text { modified from the semi-quantitative Food, } \\
\text { Frequency Questionnaire [21] }\end{array}$ & 1 & Baseline, 4-month, 12-month \\
\hline & You and Cancer & Fears of Recurrence [22] & $1 / 2$ & 4-month, 12-month \\
\hline & Your Personal costs & Designed by the study team & 2 & 4-month, 12-month \\
\hline Sexual history & Sexual History & Sexual History [23] & 1 & Baseline \\
\hline Quality of life & Your symptoms & $\begin{array}{l}\text { Head and neck radiotherapy questionnaire } \\
\text { (late toxicity) [24] }\end{array}$ & 5 & $\begin{array}{l}12 \text {-months (only people who } \\
\text { receive radiotherapy) }\end{array}$ \\
\hline Withdrawal form & Withdrawal from study & $\begin{array}{l}\text { Questions designed by the study team completed } \\
\text { by research nurse }\end{array}$ & 1 & As appropriate \\
\hline Mortality form & Place and mode of death & $\begin{array}{l}\text { Questions designed by the study team completed } \\
\text { by research nurse }\end{array}$ & 2 & As appropriate \\
\hline \multirow{3}{*}{$\begin{array}{l}\text { Quality of life additional } \\
\text { questions used in Bristol } \\
\text { participants }\end{array}$} & Your Quality of Life & $\begin{array}{l}\text { The revised University of Washington (UW) QOL } \\
\text { questionnaire }[25,26]\end{array}$ & 2 & Baseline, 4-month, 12-month \\
\hline & Difficulties in Your Life & The Social Difficulties Inventory (SDI) [27] & 2 & Baseline, 4-month, 12-month \\
\hline & Your Appearance & The Derriford Appearance Scale (DAS 24) [28] & 6 & Baseline, 4-month, 12-month \\
\hline
\end{tabular}

human papilloma virus infection in the aetiology of head and neck cancer to ensure that people understand its relevance and are not offended. Once the nurse has obtained consent s/he abstracts information on diagnosis, treatment and co-morbidity onto a short data capture form using questions based on a national audit [8]. Centres are encouraged to remind participants to complete questionnaires but this is not always possible (particularly where the time between consent and starting treatment is short). We code diagnosis using the International Classification of Diseases (ICD) version 10 [9]. We derive the clinical staging of the tumour from the $\mathrm{T}$ (characteristics of the tumour site), $\mathrm{N}$ (degree of lymph node involvement) and $M$ (absence or presence of metastases) based on the American Head and Neck Society TNM staging of head and neck cancer [10].

\section{Blood and saliva samples}

Participants are asked to provide a blood sample and a saliva sample. The research nurse collects $16 \mathrm{ml}$ of venous blood and puts this in two EDTA tubes $(10 \mathrm{ml}$ and
$6 \mathrm{ml})$. For the saliva sample the local research nurse asks the participant to rinse their mouth and once saliva is flowing in their mouth to spit (at least $1 \mathrm{ml}$ ) into a sterile screw top container. The research nurse then posts the blood tubes and saliva container to the study centre laboratory at ambient temperature in pre-paid approved packaging, meeting UN Packaging Instruction PI650. The blood samples are spun at $3500 \mathrm{rpm}$ for 10 minutes. The buffy coat layer is stored for future DNA extraction. Up to $8 \mathrm{ml}$ of plasma in total is stored in a selection of $200 \mu \mathrm{l}$ and $500 \mu \mathrm{l}$ plasma aliquots. Saliva samples are divided into seven $1 \mathrm{ml}$ samples. All samples are frozen and stored at $-80^{\circ} \mathrm{C}$ in the Avon Longitudinal Study of Parents and Children (ALSPAC) bio-sample repository (http://www.bristol.ac.uk/alspac/). DNA extraction is being carried out by LGC genomics (http://www.lgcgenomics. $\mathrm{com} /$ ). To date 2,000 buffy coat samples have been extracted using the Kleargene spin column extraction method (http://www.lgcgroup.com/products/dna-extractionkits). Samples are eluted in $1 \mathrm{ml}$ low salt buffer. DNA is quantified using picogreen, the mean DNA concentration is 
$97.21 \mathrm{ng} / \mu \mathrm{l}$, (standard deviation $46 \mathrm{ng} / \mu \mathrm{l}$ ), with a range of $<10 \mathrm{ng} / \mu \mathrm{l}$ (5 samples) to $404 \mathrm{ng} / \mu \mathrm{l} .1795$ samples have a concentration $>50 \mathrm{ng} / \mu \mathrm{l}$.

\section{Tissue samples}

We obtain tissue either from the diagnostic procedure or from the operation to remove the primary tumour. We follow a hierarchy of access protocol so that local research tissue banks have first access to tissue, with the study only receiving additional tissue where available. We ask the local pathologist to select one representative paraffin embedded tumour block from the primary site and if applicable, another from a matched lymph node metastasis. The local pathology department also send an anonymised copy of the participant's histopathology report with the tissue blocks and provide some brief details on the sample.

\section{Study follow-up}

We do not collect any further biological samples from participants. We send out follow-up questionnaire packs at four months and 12 months after the person joined the study. These questionnaires repeat many of the questions included at baseline apart from those enquiring about previous sexual behaviour. We have added questions on fear of recurrence at both four and 12 months and questions on late radio-toxicity at 12 months. The research nurses abstract updated information on diagnosis and treatment from the hospital medical record onto a short data capture form at four and 12 months. We flag study participants with the Health and Social Care Information Centre (HSCIC) and we receive regular notifications of subsequent cancer registrations and mortality among cohort members. Where someone has died we ask research nurses in study centres to complete a short questionnaire that enquires about the place and circumstances of death. When someone decides to withdraw from the study we ask the research nurses in study centres to complete a form giving the date, details and reason for withdrawal.

\section{Data management}

The Bristol study team enters data from questionnaires and the data capture form onto a central database with automatic range and logic checks to reduce data entry errors. We identify missing or inconsistent data on the data capture forms, in particular where the initial diagnosis, stage or both are inaccurate or unclear. We check data for these fields against text descriptions and pathology reports to minimise errors and missing data. We contact study centres for further details where necessary. We are carrying out double data entry on a $10 \%$ random sample of questionnaires to establish the error rate and to identify key questionnaire sections that may require double data entry for the whole cohort.

\section{Power calculation}

Our power calculation was based on survival differences across 4,000 participants. This allowed for exclusions of rarer cancer types, withdrawals from the study, incomplete data and loss to follow-up from the target total of 5,000 enrolled. We initially assumed that people would be recruited from 10 centres and allowed for clustering by centre in the power calculation. If 2 year mortality was $35 \%$ and two-sided alpha is 0.05 we calculated that we would have $80 \%$ power to detect a difference in survival of around five percentage points for an intra-class correlation coefficient (ICC) of 0.005 and of around seven percentage points for an ICC of 0.01 (according to an individual patient characteristic or a measure of the quality of care they received split at the median). We have updated our power calculation, based on our actual recruitment from 78 centres, which indicates that we will have $80 \%$ power to detect a difference in survival of around four percentage points for an ICC of 0.005 and of around five percentage points for an ICC of 0.01 .

\section{Discussion}

This large clinical cohort is successfully recruiting people with head and neck cancer from across the UK. It is on track to consent 5,000 people by the end of December 2014. The cohort recruits people before treatment starts and obtains wide-ranging consent, clinical information, self-reported socio-demographic, lifestyle and quality of life data and biological samples.

We invested considerable time building a national clinical consensus about the need for the study and in designing the protocol before we started our fieldwork. We opened to recruitment in a few centres initially to ensure the protocol ran smoothly. This meant that there was clinical support for the study and that the protocol was ready to be rolled out, but this did delay our start date and our initial rate of recruitment. The only specific problem we have encountered was when one clinician refused to allow people under his care to complete the questionnaire on sexual behaviour. We were aware that some people might find these questions sensitive so we had put them in a separate questionnaire that was handed out with a careful explanation from the research nurse.

We decided that all cancers treated by the head and neck multi-disciplinary team should be included in the study. We thought this would make the study easier to recruit to, as everyone was eligible. Even though we expect that numbers for some tumours will be modest, given the limited data on such tumours, we think that this will still be potentially valuable. 
Participants are recruited by research staff employed by NHS trusts. The hospital trusts are reimbursed indirectly through the research networks. This means we have no direct control over staffing levels or performance but on the other hand we do not have to appoint, train or manage staff locally. As we have reported previously the process of recruiting to national clinical observational studies in the UK is not straightforward and is often delayed by local processes [29]. Trusts are reimbursed for the number of people they recruit and not on the response rate or the quality of the data they collect.

This study is a resource and we encourage future collaborations to ensure it is fully exploited. We are currently creating a detailed data dictionary and formalising access arrangements. Details of these, copies of study questionnaires and updates on recruitment will be made available on our study website (http://www.headandneck5000.org.uk/). Around half of UK centres (and most of the larger centres) treating people with head and neck cancer are contributing to this study.

This study has therefore also created a national framework with capacity to recruit people with head and neck cancer into clinical research.

In conclusion we are creating a large DNA-backed clinical cohort in people with head and neck cancer. As with any large scale study it has limitations in terms of recruitment rate and completeness of data. Nevertheless we believe it will make important contributions to the study of survival in people with head and neck cancer and to prognosis research more generally. We welcome collaboration and use of the resource.

\section{Competing interests}

The authors declare that they have no competing interests.

\section{Authors' contributions}

ARN managed the project, chaired the study strategy group and drafted the manuscript. AW, KH, MJ, CP, MP, SL, ST, SR, SJT all contributed to the design and conduct of the study. CA, TJP, WH, HW, CN, SF, SNR, SJT were members of the study strategy group. All authors read and approved the final manuscript.

\footnotetext{
Acknowledgements

We would like to thank the people with head and neck cancer who took part in this study. We would also like to thank the research, laboratory and clinical staff who supported this study. We would specifically like to thank members of the Bristol co-ordinating team: Mrs Christine Wood (Research Coordinator) and Dr Martin Persson (previous project manager). We would also like to acknowledge the principal investigators at Head and Neck 5000 study sites. These include: Professor Simon Rogers (Aintree); Mr JK Thiruchelvam (Barnet \& Chase Farm); Dr Maged Abdelkader (Basildon); Mr Shahram Anari (Birmingham Heartlands); Professor Hisham Mehanna (Birmingham QEH); Dr Tom Sheehan (Boston); Dr Karen Dyker, Mr James McCaul (Bradford); Dr Richard Benson (Cambridge University Hospitals NHS Trust); Dr Simon Stewart (Charing Cross); Mr Charles Hall (Cheltenham General Hospital); Dr Jim Lester (Chesterfield Royal Hospital); Mr Jarrod Homer (Christie); Dr Abdel Hamid, Dr Alan Lamont (Colchester); Dr Lydia Fresco, Professor Hisham Mehanna (Coventry); Mr Shane Lester (Darlington Memorial Hospital); Dr Geoffrey Cogill, Dr Amy Roy (Derriford Hospital Plymouth); Dr Bernie Foran, (Doncaster Royal Infirmary); Mr Brian Bisase (East Grinstead); Mr Alistair Balfour (East Kent (Kent \& Canterbury)); Mr Andrew Evans (Fife); Dr Simon Gollins (Glan Clwyd Hospital,
}

Rhyl); Dr David Conway (Glasgow); Mr Charles Hall (Gloucestershire Royal Hospital); Dr Sinnappa P Gunasekaran (Grimsby); Mrs Laura Lees, Ms Rachel Lowe (Hereford (Wye Valley NHS Trust)); Mr James England (Hull \& East Yorks); Dr Christopher Scrase (Ipswich); Mr Richard Wight (James Cook, Middlesbrough, South Tees Hospitals NHS Foundation Trust); Dr Mehmet Sen (Leeds); Ms Margret Doyle (Leighton); Dr Russell Moule (Lister Hospital (East and North Hertfordshire NHS Trust)); Dr Kate Goodchild (Luton); Dr Nick Rowell (Maidstone); Ms Dawn Beaumont-Jewell, Dr H W Loo (Mid Essex Hospital); Dr Kate Goodchild (Mount Vernon); Dr Petra Jankowska (Musgrove Park, Taunton); Mr Vinidh Paleri (Newcastle); Dr Richard Casasola (Ninewells Hospital, Dundee); Dr Tom Roques (Norfolk and Norwich); Mr Paul Tierney (North Bristol); Dr David Hwang (North Devon District Hospital); Dr P Dyson (North Cumbria); Dr Gerard Andrade (Northampton); Mr Taran Tatla (Northwick Park); Dr Judith Christian (Nottingham University Hospitals NHS Trust); Mr Stuart Winter (Oxford); Mr Andrew Baldwin (Pennine); Dr Joe Davies, Dr Emma King (Poole); Ms Debi Barnes, Mr Costas Repanos, Dr Dae Kim (Portsmouth); Mr Stuart Richards (Rotherham); Dr Nicola Dallas (Royal Berkshire Hospital); Mr Ken McAlister (Royal Blackburn); Dr David Hwang (Royal Devon \& Exeter Hospital); Dr Sandeep Berry, Dr Naomi Cole, Dr Laura Moss (Royal Glamorgan); Dr Nachi Palaniappan, Dr Mererid Evans (Royal Gwent Hospital); Mr Jarrod Homer (Royal Manchester); Professor Christopher Nutting (Royal Marsden London); Professor Christopher Nutting (Royal Marsden Sutton); Dr Muthu Siva (Royal Preston Hospital Lancashire Teaching Hospitals NHS Foundation Trust); Mr Churunal Hari (Royal Shrewsbury and Telford Hospital NHS Trust); Dr Katie Wood (Royal Surrey County Hospital NHS Foundation Trust); Dr Richard Simcock (Royal Sussex); Mr John Waldron (Royal United Hospitals Bath); Mr Nicholas Hyde (St Georges); Dr Sinnappa P Gunasekaran, Dr Abdel Hamid (Scunthorpe General Hospital); Dr Bernie Foran (Sheffield); Dr Imtiaz Ahmed (Southend); Dr Daljit Gahir (Stoke City General); Mr James O'Hara (Sunderland Royal Hospital); Dr Ruth Carr (Torbay); Dr Martin Forster (University College London Hospital); Dr Tom Sheehan (United Lincolnshire Hospital); Professor Steve Thomas (U H Bristol); Dr Mererid Evans (U H Wales); Mrs Lynda Wagstaff (Walsall); Dr Joseph Mano, Dr Caroline Brammer (Wolverhampton); Mrs Jayne Tyler (Worcestershire); Mr Andrew Coatesworth (York). This publication presents independent research funded by the National Institute for Health Research (NIHR) under its Programme Grants for Applied Research scheme (RP-PG-0707-10034). The views expressed in this publication are those of the author(s) and not necessarily those of the NHS, the NIHR or the Department of Health.

\section{Author details}

${ }^{1}$ National Institute for Health Research (NIHR) Biomedical Research Unit in Nutrition, Diet and Lifestyle at the University Hospitals Bristol NHS Foundation Trust and the University of Bristol and School of Oral and Dental Sciences, University of Bristol, Bristol, UK. ${ }^{2}$ School of Oral and Dental Sciences, University of Bristol, Bristol, UK. ${ }^{3}$ Surgical Research Team, University Hospitals Bristol NHS Foundation Trust, Bristol, UK. ${ }^{4}$ School of Social and Community Medicine, University of Bristol, Bristol, UK. ${ }^{5}$ National Cancer Research Institute Consumer Liaison Group (NCRI CLG) and Independent Cancer Patients Voice (ICPV), London, UK. ${ }^{6} \mathrm{MRC}$ Integrative Epidemiology Unit and Avon Longitudinal Study of Parents and Children, School of Social and Community Medicine, University of Bristol, Bristol, UK. ${ }^{7}$ School of Clinical Sciences, University of Bristol, Bristol, UK. ${ }^{8}$ Cochrane Oral Health Group, School of Dentistry, University of Manchester, Manchester, UK. ${ }^{9}$ Royal Marsden Hospital and the Institute for Cancer Research, London, UK. ${ }^{10}$ Leeds Institute for Cancer and Pathology, University of Leeds, Leeds, UK. ${ }^{11}$ Evidence-Based Practice Research Centre (EPRC), Faculty of Health and Social Care, Edge Hill University, Ormskirk, Lancashire, UK.

Received: 28 November 2014 Accepted: 10 December 2014 Published: 17 December 2014

\section{References}

1. Mehanna H, Paleri V, West CML, Nutting C: Head and neck cancer-part 1: epidemiology, presentation, and prevention. Brit Med J 2010, 341:C4684.

2. Mehanna H, West CML, Nutting C, Paleri V: Head and neck cancer-part 2: treatment and prognostic factors. Brit Med J 2010, 341:c4690.

3. Drugan C, Leary S, Mellor T, Bain C, Verne J, Ness A, Thomas S: Head and neck cancer in the south west of England, Hampshire, and the Isle of Wight: trends in survival 1996-2008. Brit J Oral Max Surg 2013, 51(1):19-24.

4. Goulart BHL, Ramsey SD, Parvathaneni U: Observational study designs for comparative effectiveness research: an alternative approach to close 
evidence gaps in head-and-neck cancer. Int J Radiat Oncol 2014, 88(1):106-114.

5. Hemingway H, Riley RD, Altman DG: Ten steps towards improving prognosis research. Brit Med J 2009, 339:b4184.

6. Hemingway $H$, Croft P, Perel P, Hayden JA, Abrams K, Timmis A, Briggs A, Udumyan R, Moons KGM, Steyerberg EW, Roberts I, Schroter S, Altman DG, Riley RD, PROGRESS Group: Prognosis research strategy (PROGRESS) 1: a framework for researching clinical outcomes. Brit Med J 2013, 346:e5595.

7. Hughes C, Homer J, Bradley P, Nutting C, Ness A, Persson M, Jeffreys M, Waylen A, Leary S, Thomas S: An evaluation of current services available for people diagnosed with head and neck cancer in the UK (2009-2010). Clin Oncol-Uk 2012, 24(10):E187-E192.

8. The UK National Head and Neck Audit. [http://www.hscic.gov.uk/headandneck]

9. ICD-10 Version: International Statistical Classification of Diseases and Related Health Problems 10th Revision. http://www.who.int/classifications/icd/en/]

10. Deschler D, Day T: TNM Staging of Head and Neck Cancer/Neck dissection classification. Alexandria (VA): American Academy of Head and Neck Surgery; 2008

11. Adult co-morbidity evaluation-27. [http://www.hscic.gov.uk/catalogue/ PUB14257/clin-audi-supp-prog-head-neck-dahn-12-13-rep18.pdf]

12. Lagiou P, Georgila C, Minaki P, Ahrens W, Pohlabeln H, Benhamou S, Bouchardy C, Slamova A, Schejbalova M, Merletti F, Richiardi L, Kjaerheim K, Agudo A, Castellsague X, Macfarlane TV, Macfarlane GJ, Talamini R, Barzan L, Canova C, Simonato L, Lowry R, Conway DI, McKinney PA, Znaor A, McCartan BE, Healy C, Nelis M, Metspalu A, Marron M, Hashibe M, Brennan PJ: Alcohol-related cancers and genetic susceptibility in Europe: the ARCAGE project: study samples and data collection. Eur J Cancer Prev 2009, 18(1):76-84.

13. Benzeval M, Der G, Ellaway A, Hunt $K$, Sweeting $H$, West $P$, Macintyre $S$ : Cohort profile: west of scotland twenty-07 study: health in the community. Int J Epidemiol 2009, 38(5):1215-1223.

14. Brooks RG, Rabin F, De Charro F: The measurement and valuation of health status using EQ-5D: a European perspective:evidence from the EuroQol BIOMED Research Programme. Kluwer Academic Publishers; 2003.

15. The Million Women Study. [http://www.millionwomenstudy.org/introduction/]

16. The CLEAR study. [http://clearstudy.org.au/about-clear-study/\#.U15paflSYgg]

17. Scheier MF, Carver CS, Bridges MW: Distinguishing optimism from neuroticism (and trait anxiety, self-mastery, and self-esteem): a reevaluation of the Life Orientation Test. J Pers Soc Psychol 1994, 67(6):1063-1078.

18. Aaronson NK, Ahmedzai S, Bergman B, Bullinger M, Cull A, Duez NJ, Filiberti A, Flechtner H, Fleishman SB, Dehaes JCJM, de Haes JC, Kaasa S, Klee M, Osoba D, Razavi D, Rofe PB, Schraub S, Sneeuw K, Sullivan M, Takeda F: The European-organization-for-research-and-treatment-of-cancer Qlq-C30 - a quality-of-life instrument for use in international clinical-trials in oncology. J Natl Cancer / 1993, 85(5):365-376.

19. Bjordal K, Kaasa S, Ahlnerelmqvist M, Tollesson E, Bonde A: Development of a head and neck cancer-specific module for use with the Eortc core quality-of-life questionnaire (Eortc Qlq-C30). Qual Life Res 1993, 2(1):72.

20. Zigmond AS, Snaith RP: The hospital anxiety and depression scale. Acta Psychiat Scand 1983, 67(6):361-370.

21. Willett WC, Sampson L, Stampfer MJ, Rosner B, Bain C, Witschi J, Hennekens $\mathrm{CH}$, Speizer FE: Reproducibility and validity of a semiquantitative food frequency questionnaire. Am J Epidemiol 1985, 122(1):51-65.

22. Humphris G, Ozakinci G: The AFTER intervention: a structured psychological approach to reduce fears of recurrence in patients with head and neck cancer. Br J Health Psychol 2008, 13(Pt 2):223-230.

23. Castellsague X, Bosch FX, Munoz N, Meijer CJLM, Shah KV, De Sanjose S, Eluf-Neto J, Ngelangel CA, Chichareon S, Smith JS, Herrero R, Moreno V, Franceschi S, International Agency for Research on Cancer Multicenter Cervical Cancer Study Group: Male circumcision, penile human papillomavirus infection, and cervical cancer in female partners. New Engl J Med 2002, 346(15):1105-1112.

24. Ho KF, Farnell DJJ, Routledge JA, Burns MP, Sykes AJ, Slevin NJ, Davidson SE: Developing a CTCAEs patient questionnaire for late toxicity after head and neck radiotherapy. Eur J Cancer 2009, 45(11):1992-1998.

25. Hassan SJ, Weymuller EA Jr: Assessment of quality of life in head and neck cancer patients. Head Neck 1993, 15(6):485-496.

26. Rogers SN, Gwanne S, Lowe D, Humphris G, Yueh B, Weymuller EA Jr: The addition of mood and anxiety domains to the University of Washington quality of life scale. Head Neck 2002, 24(6):521-529.
27. Wright EP, Kiely M, Johnston C, Smith AB, Cull A, Selby PJ: Development and evaluation of an instrument to assess social difficulties in routine oncology practice. Qual Life Res 2005, 14(2):373-386.

28. Carr T, Moss T, Harris D: The DAS24: a short form of the Derriford Appearance Scale DAS59 to measure individual responses to living with problems of appearance. Br J Health Psychol 2005, 10(Pt 2):285-298.

29. Sandy J, Kilpatrick N, Persson M, Bessel A, Waylen A, Ness A, Ireland A: Why are multi-centre clinical observational studies still so difficult to run? Br Dent J 2011, 211(2):59-61.

doi:10.1186/1471-2407-14-973

Cite this article as: Ness et al:: Establishing a large prospective clinical cohort in people with head and neck cancer as a biomedical resource: head and neck 5000. BMC Cancer 2014 14:973.

\section{Submit your next manuscript to BioMed Central and take full advantage of:}

- Convenient online submission

- Thorough peer review

- No space constraints or color figure charges

- Immediate publication on acceptance

- Inclusion in PubMed, CAS, Scopus and Google Scholar

- Research which is freely available for redistribution

Submit your manuscript at www.biomedcentral.com/submit
C) BioMed Central 